\title{
Collaborative Decision for Building Energy System on Traditional Markets in Urban Areas
}

\author{
Christiono Utomo ${ }^{1 *}$, Yani Rahmawati ${ }^{1}$, Nugroho Priyo Negoro ${ }^{1}$ \\ ${ }^{1}$ Institut Teknologi Sepuluh Nopember \\ *christiono@ce.its.ac.id
}

\begin{abstract}
It becomes more important to design energy-efficient for buildings. This is true in relationship to a public building design especially retail property such as traditional market. It calculates the use of energy during construction and operation. There are three alternatives for a building energy system which are passive energy, electrical equipment, and user processes. The alternatives are developed for a public commercial retail. They were selected by four stakeholders named government, tenant, designer, and property manager. It is not easy to make a decision where there are many stakeholders' interests. A decision support system is necessary. The system should support a collaborative process among decision makers. This paper presents a multi criteria and multi person decision process to develop agreement options and coalition formation to find the best fit option of the energy system for traditional markets building in urban areas. There are three stages involved in the process which are first is determining and scoring of every alternative for every stakeholder, second is determining the optimal solution (payoff optimum) for each stakeholder in a coalition, and third is analyzing the best fit options for every coalition and grand coalition. An analytical hierarchy process (AHP) based on satisfying option is applied for the first stage. A liner programming is used to determine payoff optimum in the stage two and an agent system based on game theory built the coalition algorithm on the stage three. The result shows a model of collaborative decision to select a building system at design process.
\end{abstract}

Keywords—Energy system, collaborative, decision, traditional markets building, urban area

\section{INTRODUCTION}

$\mathrm{T}$ he importance of energy-efficient in a building is becoming more important. It can be controlled during design stage. Designs of a new building display an increasing awareness of sustainability. Decision must be made on the energy system for traditional market that involving all stakeholders as decision makers. They are government, customer/tenant, designer, and property manager.

Traditional markets are buildings that built and managed by government or local government, including cooperation with private businesses. The building is filled by shops, kiosks, and stalls. It is rented by smallscale business with small capital. The process of buying and selling goods is to bargain.

This paper presents a support for collaborative decision to select building energy system on traditional market in urban area. The available alternatives for building energy system are based on research presented by [1], which are passive energy, electrical equipment and user process.

1. Passive energy. This alternative utilizes an architectural concept of passive energy buildings; maximum opening wall for natural lighting and air conditioning.

2. Electrical equipment. It utilizes electrical equipment for example, lighting and air conditioners.

3. 'User processes' means that the utilization of energy for a building depends on the 'user processes'. It processes throughout life cycle of buildings; no electrical equipment is provided.

\section{CONCEPTUAL FRAMEWORK OF COLLABORATIVE DECISION}

Collaborative design is found to be an essential factor in achieving the sustainable design [2]. Its importance in supporting the production of sustainable design is placed on the involvement of multi parties with different expertise in design process and also their contribution in developing design from early until final stage of design. It can be applied as an approach to decide best fit option of sustainable design. This is also found in the previous studies [3, 4, and 5].

The essential meaning of collaboration is unique, where it cannot be classified similarly with the meaning of cooperation. It is also different with the meaning of coordination. With the intention to achieve best design, the concept of collaboration becomes important approach in achieving sustainability. Collaborative design is described as an effort to integrate multiple parties in achieving best design mutually by concerning the best shared-goal that satisfy all the parties [6].

Integration is vital for the performance of collaborative design. There are two main aspects that are needed to be integrated, which are tangible and intangible aspects [7]. During design process, each expertise is encouraged to share their knowledge. The knowledge relates with their thoughts, experiences and any information regarded with sustainable building design i.e. regulations and requirements. The knowledge is included as intangible aspect, where it is also classified into tacit and explicit knowledge [8], meanwhile the tangible aspect consist of design drawings, and the results of design developments.

The two aspects are needed to be integrated in order to achieve successful collaboration. The involvement of 
various participants makes it difficult to be realized, in which it is not only based on their different backgrounds, but also their different availabilities in conducting the design meetings. Previous studies developed systems and tools to support the design collaboration, especially the virtual design [9, 10, and 11]. Based from review conducted by [7], it is found that decision making and negotiation are two vital activities in supporting the collaboration as well as the integration, especially in finding the best design option for the sustainability. The importance of it also can be found in the previous studies, in which the advance researches or applications of collaboration in decision making and negotiation can also be found [12, 13, and 14].

\section{METHOD}

\section{A. Function Analysis of Sustainability}

Function analysis is a technique that oriented to the required functions on each item or system reviewed to produce the desired product value. The analysis is used to describe the main function of the product, describes the classification of the primary functions and the secondary functions to obtain a comparison between cost and worth required. For some functions it may be decided that a set of generic process is needed to perform the function, each of which will give rise to an associated set of possible specific processes. Based on the process of function analysis system technique (FAST) [15], there are three sustainability functions that are technical, economic, and social sustainability. Technical sustainability measures the age of use of the building and how its building value is maintained over its lifetime. Economic sustainability measures how the building can be accessed by its users as planned, and the social sustainability measures how buildings benefit society in accordance with the planned function. A number of processes identified as being probable alternatives for performing the function.

\section{B. Life Cycle Cost of System Development}

Life cycle cost (LCC) is a technique to evaluate the economic value of energy system by calculating all relevant costs during the investment period through adjustment to time value of money. The LCC application method involves a combination of managerial, financial and technical expertise in all phases of life-cycle. The main purpose of this LCC is to evaluate alternative solutions to specific design problems. LCC is conducted as a basis for decisions between alternatives and may also be done as an independent study, or it may be part of a more comprehensive study.

LCC in this paper refers to development process [16] of a property building as it is the traditional market building. The process follows the development stages in the form of inception, design, formal negotiation, construction, and property management. LCC as development cost consist of capital expenditure, energy cost, operation and maintenance (O\&M) cost, and replacement cost. In this case, salvage value was not calculated because it was not a practice in Indonesia. It is difficult to separate energy system cost from the total cost of building because some of the energy system is part of whole system of the building.

In the collaborative decision, perspective of LCC is different among stakeholders. Property management uses the LCC to estimate the amount of costs so that they can convince the tenant for the savings. It can assure that the building is more valuable than other buildings. While the goal of tenants is to obtain high building value, low cost management, and make tenants safe and happy and long lease time.

\section{Building Energy System Selection}

Figure 1 shows a model of decision hierarchy based on life cycle cost (development cost) and sustainable function (sustainability) for a traditional market on urban area in Indonesia. Each of the objects in this model contains attribute representing their various properties and different preferences [12]. The goal of the problem ( $\mathrm{G}=$ "to select energy system of traditional markets building in urban area") is addressed by some alternatives $(\mathrm{A}=\mathrm{a} 1 ; \mathrm{a} 2 ; \mathrm{a} 3)$. The problem is split into sub problems (c) and (f) which are the evaluation criteria.

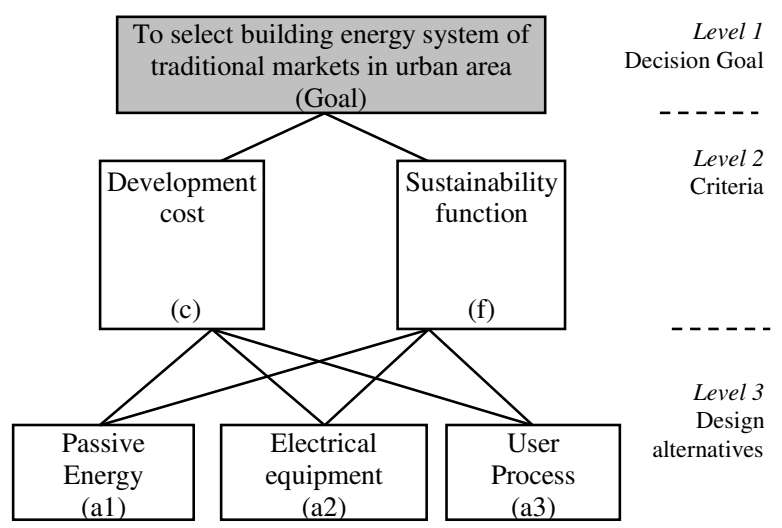

Figure 1. Decision hierarchy of building energy system

\section{RESULTS AND DISCUSSION}

\section{A. Value-based Criteria}

The technical solution options for building energy system were categorized into 'Cost' identified by development cost; and 'Function' by three sustainability functions. Table 1 shows the select ability (Ps) and reject ability (Pr) of a satisfying option [17] that represents function and cost of technical solution for building energy system respectively. The value of each alternative is calculated based on value equation that is function/cost The greater the number the greater the value. The best alternative is alternatives with the highest value. The table presents the difference of best option among stakeholder. The choice of government is different from the choice of tenant. This can be understood because of differences of interest. For tenants of traditional markets with limited economic capabilities, the choice of the user system fits perfectly with the tenant's interests. The use of the energy system follows the flexibility of their economic capabilities. Electrical systems are selected by property managers. This is understandable because the cost of electricity usage is borne by the tenant with a net lease system. Electricity payment is made by management in the form of service charge. It becomes a 
business income for property management.

Table 1 . Value of alternatives by each stakeholder

\begin{tabular}{|c|c|c|c|}
\hline \multicolumn{4}{|c|}{ SH1: Government } \\
\hline & $\begin{array}{c}\text { Ps } \\
\text { (Function) } \\
\text { Development }\end{array}$ & $\begin{array}{c}\text { Pr } \\
\text { (Cost) } \\
\text { Sustainability }\end{array}$ & $\begin{array}{c}\text { Value }= \\
\text { Function/Cost }\end{array}$ \\
\hline (a1) Passive & 0.612698 & 0.132573 & 4.621583 \\
\hline (a2) Electrical & 0.117989 & 0.492137 & 0.239749 \\
\hline (a3) User & 0.269312 & 0.375289 & 0.717612 \\
\hline \multicolumn{4}{|c|}{ SH2: Customer/ Tenant } \\
\hline & $\begin{array}{c}\text { Ps } \\
\text { (Function) } \\
\text { Development }\end{array}$ & $\begin{array}{c}\text { Pr } \\
\text { (Cost) } \\
\text { Sustainability }\end{array}$ & $\begin{array}{c}\text { Value }= \\
\text { Function/Cost }\end{array}$ \\
\hline (a1) Passive & 0.137288 & 0.093241 & 1.472393 \\
\hline (a2) Electrical & 0.239488 & 0.49447 & 0.484332 \\
\hline (a3) User & 0.623225 & 0.412289 & 1.511622 \\
\hline \multicolumn{4}{|c|}{ SH3: Designer } \\
\hline & $\begin{array}{c}\text { Ps } \\
\text { (Function) } \\
\text { Development }\end{array}$ & $\begin{array}{c}\text { Pr } \\
\text { (Cost) } \\
\text { Sustainability }\end{array}$ & $\begin{array}{c}\text { Value }= \\
\text { Function/Cost }\end{array}$ \\
\hline (a1) Passive & 0.093382 & 0.093241 & 1.001514 \\
\hline (a2) Electrical & 0.685294 & 0.49447 & 1.385916 \\
\hline (a3) User & 0.221324 & 0.412289 & 0.536817 \\
\hline \multicolumn{4}{|c|}{ SH4: Property Management } \\
\hline & $\begin{array}{c}\text { Ps } \\
\text { (Function) } \\
\text { Development }\end{array}$ & $\begin{array}{c}\text { Pr } \\
\text { (Cost) } \\
\text { Sustainability }\end{array}$ & $\begin{array}{c}\text { Value }= \\
\text { Function/Cost }\end{array}$ \\
\hline (a1) Passive & 0.127949 & 0.093241 & 1.372233 \\
\hline (a2) Electrical & 0.78487 & 0.49447 & 1.587296 \\
\hline (a3) User & 0.087181 & 0.412289 & 0.211456 \\
\hline
\end{tabular}

\section{B. Agreement Options and Coalition}

The framework of collaborative decision is developed base on agreement option and coalition [18]. It is applied for selection of building energy system on traditional market in urban area. Four stakeholders (Figure 2) that are SH1 government, $\mathrm{SH} 2$ customer/tenant, $\mathrm{SH} 3$ designer, and SH 4 property manager are involved and gave their own preference. Once every stakeholder is aware of the options, they analyze to determine what they will get, gain or loss if each alternative is selected. This agreement options process provides additional functionality to negotiate a joint representation of the problem. All stakeholders share the same goal but each has his/her own set of activities.

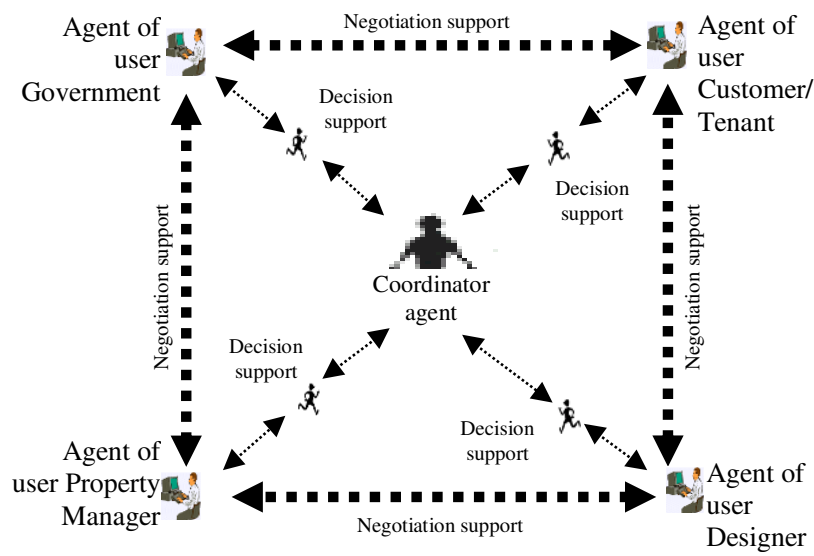

Figure 2: System architecture collaboration

Stakeholder of multi-criteria decision making problems usually evaluates the alternative solution from different perspective, making it possible to have a dominant solution among the alternatives. Each stakeholder needs to identify the goals that can be optimized and those that can be compromised in order to reach an agreement with other stakeholders. The agreement options acts as a solution filter. Only promising solution are available to stakeholders for detailed collaboration.

Collaboration has coalition formation algorithms. This research employs multiple coalition formation algorithms. First is coalition formation, second is solution options ranking for the individual and group. The stakeholders are the parties in the building energy system selection. There are three stages to determine the collaborative decision. The first stages came from individual decision. It is start from the output of AHP process that is scoring every alternative [5]. The results from this first stages are used to determine the agreement options in the last two stages. The stages are:

1. Determining and scoring of every alternative for every stakeholder. Figure 3 show that stakeholders had different best option as an alternative solution.

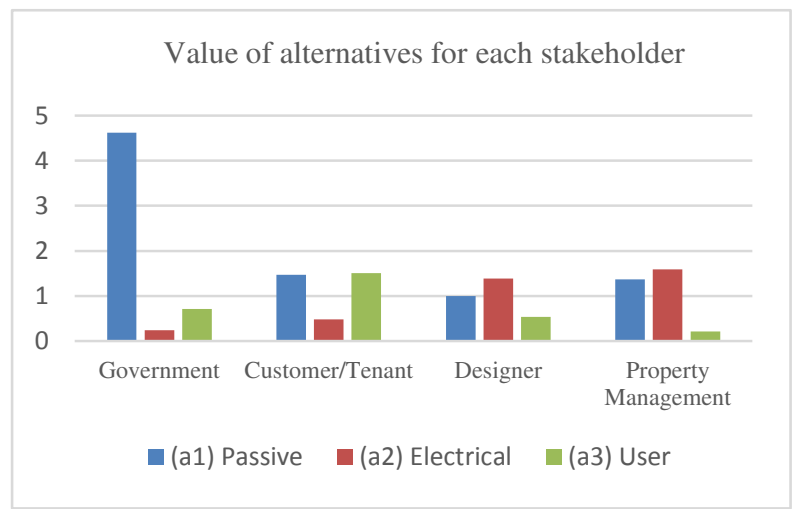

Figure 3. Value of alternatives for each stakeholder

2. Determining the optimal solution (payoff optimum) for each stakeholder in a coalition is based on a cooperative multi-person games in which coalitionformation among sub-group members are allowed [18]. A linear programming formula is used to determine the Pareto optimal for each stakeholder in each coalition. Table 2 presents the determination of payoff optimum. The value of (max-min) payoff for a stakeholder is used to determine the payoff optimum by applying the coordinating scenario. This means that no one stakeholder has higher importance than others. This scenario can be changed depending on the situation of a project.

Table 2. Payoff optimum for each coalition

\begin{tabular}{cccccc}
\hline Coalition & \multicolumn{3}{c}{ Alternatives } & \multicolumn{2}{c}{ Payoff Optimum } \\
\hline SH1+2+3+4 & a1 & a2 & a3 & Max-min & Optimum \\
\hline SH1 & 0.096 & 0.507 & 0.397 & 0.410 & 0.507 \\
SH2 & 0.080 & 0.530 & 0.391 & 0.450 & 0.530 \\
SH3 & 0.403 & 0.417 & 0.180 & 0.237 & 0.417 \\
SH4 & 0.223 & 0.087 & 0.120 & 0.263 & 0.421 \\
& 0.579 & 1.454 & 0.967 & & 1.454 \\
\hline
\end{tabular}

3. Stage three is analyzing the best fit options for every coalition and grand coalition. The result is presented on Table 3. It also presents the result of priorities of the technical solution for building energy system selection. 
Determining the fitness factor is applied to both value criteria namely function of sustainability and cost of development. Categorization of best options is value that is counted from function/cost. Table 3 reveals that none of the solutions will not become an option because one individual stakeholder or coalition of stakeholders desires to select it. The best select ability option is the one with the least negative value. If the negative value is close to zero, then most stakeholders earn a payoff close to their Pareto optimum. A high negative value means that some stakeholders earn higher than their Pareto optimum.

It can be seen that each alternative is chosen as agreement options for all stakeholders. Alternative solution of passive energy (a1) is an option. Although it is the last choice for the whole process of collaboration, that alternative becomes an option for the coalition between property manager and tenant. The table indicates that 'electrical system' (a2) is the best solution. The best means that the option is the most selected in all individual and also all coalition.

Table 3. Ranking of building energy system solution

\begin{tabular}{llll}
\hline \multirow{2}{*}{$\begin{array}{c}\text { Alternatives ranking for each } \\
\text { stakeholder and coalition }\end{array}$} & \multicolumn{3}{c}{ Ranking alternative } \\
\cline { 2 - 4 } SH1 (Government) & $\mathrm{a} 1$ & $\mathrm{a} 2$ & $\mathrm{a} 3$ \\
\hline SH2 (Customer/Tenant) & $2^{\text {st }}$ & $3^{\text {rd }}$ & $2^{\text {nd }}$ \\
\hline SH3 (Designer) & $3^{\text {rd }}$ & $1^{\text {st }}$ \\
\hline SH4 (Property Management) & $1^{\text {st }}$ & $3^{\text {rd }}$ \\
\hline Coalition SH1 and SH2 & $1^{\text {st }}$ & $3^{\text {rd }}$ \\
\hline Coalition SH1 and SH3 & $2^{\text {nd }}$ & $3^{\text {rd }}$ & $1^{\text {st }}$ \\
\hline Coalition SH1 and SH4 & $2^{\text {nd }}$ & $1^{\text {st }}$ & $3^{\text {rd }}$ \\
\hline Coalition SH2 and SH3 & $2^{\text {nd }}$ & $1^{\text {st }}$ & $3^{\text {rd }}$ \\
\hline Coalition SH2 and SH4 & $3^{\text {rd }}$ & $2^{\text {nd }}$ & $1^{\text {st }}$ \\
\hline Coalition SH3 and SH4 & $1^{\text {st }}$ & $3^{\text {rd }}$ & $2^{\text {nd }}$ \\
\hline Coalition SH1, SH2, SH3 & $2^{\text {rd }}$ & $1^{\text {st }}$ & $3^{\text {rd }}$ \\
\hline Coalition SH1, SH2, SH4 & $2^{\text {nd }}$ & $3^{\text {rd }}$ & $1^{\text {st }}$ \\
\hline Coalition SH2, SH3, SH4 & $2^{\text {nd }}$ & $3^{\text {rd }}$ & $1^{\text {st }}$ \\
\hline Grand Coalition $(\mathrm{All} \mathrm{Stakeholders)}$ & $2^{\text {nd }}$ & $1^{\text {st }}$ & $3^{\text {rd }}$ \\
\hline RESULT & $3^{\text {rd }}$ & $1^{\text {st }}$ & $1^{\text {st }}$ \\
\hline & & $2^{\text {nd }}$ \\
\hline
\end{tabular}

\section{CONCLUSION}

The paper deals with a technique during selection of a building energy system alternative for traditional market on urban area. Specificity of the object are the owning of public building and the characteristic of traditional market in urban area. The process is conducted by identifying the agreement options among stakeholders. The technique is based on cooperative n-person. The application of this collaborative model shows that the best choice can be achieved among traditional market stakeholders. Value of the best fit option is formed by the comparison between the sustainability function and its development cost.
Advanced research is needed, primarily in the study of automation on collaborative decision. Future research in the application of this methodology in many field of decision will build a wide range of knowledge to solve the theoretical and practical gap in automated design and automated decision.

\section{ACKNOWLEDGMENT}

The authors appreciate the recognition and awards in forms of research grant and fellowship from "Penelitian Unggulan Perguruan Tinggi (PUPT) 2017 based on contract number 563/PKS/ITS/2017"

\section{REFERENCES}

[1] C. Utomo and A. Idrus, "Life cycle cost and function analysis in value based decision" in Biondini \& Frangopol (eds), Life-Cycle Civil Engineering. London, Taylor and Francis Group, 2008, pp. 889-894.

[2] C. Utomo, and Y. Rahmawati, "The achievement to sustainability on vertical housing development through whole system design", $3^{\text {rd }}$ International Seminar on Tropical Eco Settlements. Jakarta, 31 Oct 2012.

[3] Y. Rahmawati, C. Utomo, N. Anwar, C.B. Nurcahyo, and N.P. Negoro, "Theoretical framework of collaborative design issues", Jurnal Teknologi, vol. 70, no. 7, pp. 4753, 2014.

[4] S.C.Y. Lu, W. Elmaraghy, G. Schuh, and R. Wilhelm, "A scientific foundation of collaborative engineering", Annals of the CIRP, vol. 56, no. 2, pp. 605-634, 2007.

[5] F. Detienne, "Collaborative design: managing task interdependencies and multiple perspective", Journal of Interacting with Computer, vol. 18, pp.1-20, 2006.

[6] C. Utomo, Y. Rahmawati, Suhartono, and N.P. Negoro, "A concept toward decision support for collaborative urban heritage selection", Journal of Sustainable Development, vol. 8, no. 8, 2015.

[7] Y. Rahmawati, C. Utomo, N. Anwar, N.P. Negoro, and C.B. Nurcahyo, "A framework of knowledge management for successful group decision in design process", IEEE Conference on Open Systems, Subang Jaya, 26-28 Oct 2014.

[8] Y. Rahmawati, and C. Utomo, "The influence of knowledge management to successful collaborative design", IEEE Conference on Information Technology, Computer and Electrical Engineering, Semarang, 7-8 Nov. 2014.

[9] M.D. Gross, D.E. Yi-L., R.J. McCall, W.V. Citrin, P. Hamill, A. Warmack, and K.S. Kuczun, "Collaboration and coordination in architectural design: approaches to computer mediated teamwork", Automation in Construction 7, pp. 465-473, 1998.

[10] T. Kvan, "Collaborative design: what is it?" Automation in Construction, vol. 9, pp. 409-415, 2000.

[11] C. Utomo, and Y. Rahmawati, "Knowledge and protocol on collaborative design selection", IEEE Conference on Information Technology, Computer and Electrical Engineering, Semarang, 7-8 Nov. 2014.

[12] C. Utomo, R.M. Zin, R. Zakaria, and Y. Rahmawati, "A conceptual model of agreement options for value-based group decision on value management", Jurnal Teknologi, vol. 70, no. 7, pp. 47-53, 2014.

[13] C. Utomo, N. Krisnawaty, and Y. Rahmawati, "Automated negotiation for non-producing management decision", Int'l Conference on Advanced Mechatronics, Intelligent Manufacture, and Industrial Automation (ICAMIMIA 2015), Surabaya 15-17 Oct. 2015. 
[14] Y. Rahmawati and C. Utomo, "Media support for elicitation in virtual multidisciplinary design", Int'l Conference on Advanced Mechatronics, Intelligent Manufacture, and Industrial Automation (ICAMIMIA 2015), Surabaya 15-17 Oct 2015

[15] C.W. Bytheway, FAST Creativity and Innovation: Rapidly Improving Processes, Product Development and Solving, J. Ross Pub., 2007.

[16] M.E. Miles, M.N. Laurence, and S. Adrienne. Real Estate Development: Principles and Process. $4^{\text {th }}$ ed., Urban Land Institute, 2007.
[17] W.C. Stirling, Satisfying Games and Decision Making with Applications to Engineering and Computer Science, Cambridge University Press, Cambridge, UK, 2003.

[18] C. Utomo, A. Idrus and M. Napiah, "Methodology for multi criteria group decision and negotiation support on value-based decision", In proceeding of the International Conference on Advanced Computer Control (ICACC). Singapore, IACSIT and IEEE, pp. 365-369, 22-24 Januari 2009. 